\title{
Exploring the relationship between working history, retirement transition and women's life satisfaction
}

\author{
Elisa Tambellini \\ Department of Political and Social Sciences, University of Bologna, Bologna, Italy \\ ${ }^{\star}$ Corresponding author. Email: elisa.tambellini2@unibo.it
}

(Accepted 13 August 2021)

\begin{abstract}
How does the transition to retirement affect female subjective wellbeing? The major theoretical perspectives that have been applied as frameworks to study the heterogeneous adjustment to retirement include role theory and continuity theory. They have often been integrated with a lifecourse approach, which allows us to study retirement as a transition set inside a lifelong process. In this paper, I assess how working life courses are related to changes in subjective wellbeing before and after retirement, using data from the Survey of Health, Ageing and Retirement in Europe (SHARE) and concentrating on women. Firstly, I conduct sequence analysis and cluster analysis to identify groups of typical working lifecourses from ages 20 to 50. Secondly, regression models estimate how retirement transition is associated with changes in life satisfaction, according to the different working trajectories. The results show that some of the trajectories, constituted of discontinuity or part-time periods, exhibit a continuous increase in life satisfaction, passing from employment (or unemployment) to retirement. For other trajectories, such as the full-time one, retirement seems not to have implications for subjective wellbeing.
\end{abstract}

Keywords: women; retirement transition; subjective wellbeing; working trajectories

\section{Introduction}

The transition from work to retirement is an important event in later life. The way individuals adapt to retirement has been a focus of interest for researchers in various scientific disciplines, such as epidemiology, psychology and sociology. The nature of retirement has changed enormously over the past few decades. Until 1960, retirement was generally considered a 'crisis' event, creating a challenge to personal wellbeing (Van Solinge and Henkens, 2008). Nowadays, retirement is commonly seen as a new phase of life which offers opportunities for the

(C) The Author(s), 2021. Published by Cambridge University Press. This is an Open Access article, distributed under the terms of the Creative Commons Attribution-NonCommercial-ShareAlike licence (https://creativecommons.org/licenses/ by-nc-sa/4.0/), which permits non-commercial re-use, distribution, and reproduction in any medium, provided the same Creative Commons licence is included and the original work is properly cited. The written permission of Cambridge University Press must be obtained for commercial re-use. 
development of new identities, roles and lifestyles (Mein et al., 2003; Wang, 2007). It is no longer associated with a conclusion (limited social roles, declining health, etc.), but can be described as the beginning of a third age of adulthood (Freedman, 1999).

This change in the nature of retirement, due in part to a continuous increase in life expectancy, the better health status of the retired, and their willingness to remain active in family and community roles, has increased the academic interest in the nature of retirement transition and how people live in retirement (Price and Nesteruk, 2010). Representing a border between the middle age before retirement and a new stage of life (Ekerdt, 2010), retirement is a significant event in the context of the stabilisation of general health and successive developments in later life (Henning et al., 2016). Understanding how people cope with the new challenges this stage presents could help us to comprehend how people can maintain wellbeing and health even at older ages (Henning et al., 2016).

However, investigations focused on the influence of the retirement transition on quality of life have arrived at mixed results, and few studies have focused specifically on women. Current knowledge about the issue is primarily focused on men or on gender comparison (Price and Joo, 2005). Women's careers are often marked by interruptions or part-time employment which are often not considered in the active ageing debate (Foster, 2011; König, 2017). Career interruptions, caused by the birth of children, often produce great differences between the work histories of men and women (Foster, 2011). For these reasons, it could be important to study female retirement adaptation as a standalone phenomenon since the whole process of retirement could be a different experience for women, because of the differences in their attachment to and participation in the labour force. When men leave their jobs, they are exiting from a role that has typically dominated their adult years. On the contrary, women, who commonly experience greater discontinuity in their working life (Sorensen, 1983; Clausen and Gilens, 1990; Moen, 2001), may have a different attachment to the role of 'worker' and a different adaptation to retirement.

A further limitation of previous analyses in studying the relationship between the transition to retirement, subjective wellbeing and the characteristics of the work history is that the information on work or employment has often been limited to a specific time-point, such as the last employment before retirement, without taking into account the influence of the entire working lifecourse. This strategy conflicts with one of the key principles of the lifecourse perspective, which suggests the incorporation of individual events into the different life trajectories and the consideration of their length and development (Elder et al., 2003).

The main goal of this paper is to investigate the change in subjective wellbeing of European women before and after the retirement transition, using data from the Survey of Health, Ageing and Retirement in Europe (SHARE). I am interested in understanding if a change in the quality of life exists, and how various pre-retirement working trajectories are associated with this change. Women's work status (full-time, part-time, inactivity and unemployment) will be observed during their entire lifecourse; then the career structure will be related to the variation in wellbeing associated with withdrawal from the paid labour market. At the methodological level, sequence analysis and panel analysis techniques will be implemented. 


\section{Theoretical framework}

Retirement is an important event that represents the start of a new lifestage in which work is no longer dominant, new opportunities present themselves, and both positive and negative changes can happen. Individuals have to adjust to this life change and pursue psychological wellbeing in retirement (Van Solinge, 2015). Furthermore, the retirement process itself is changing and it is transforming. In periods of high unemployment, in most Western countries older workers were frequently pushed into early retirement to enable younger workers to enter the labour market (Blossfeld et al., 2006; Ebbinghaus, 2006) and to keep the workforce competitive and adaptable to economic transformation (Buchholz et al., 2011). However, due to population ageing and the increasing financial burden of pensions, a reverse trend can be observed since the beginning of 2000 (Ebbinghaus and Hofäcker, 2013; König, 2017). That is, in recent years, many countries have had the goal of keeping older workers in the workforce by closing paths to early retirement (König, 2017). On the other hand, the increase in longevity means that retirement is becoming more a mid-life transition rather than a transition to old age; and retiring people often acquire new roles, continue to take on other roles (e.g. friend or spouse) and develop new identities (Kim and Moen, 2001).

Research on the effects of retirement on wellbeing has shown very mixed conclusions. Some studies indicate that retirement is basically good for individual physical and psychological health (Reitzes et al., 1996; Isaksson and Johansson, 2000; Latif, 2011), whereas the opposite effect has also been empirically supported (Richardson and Kilty, 1991; Kim and Moen, 2002). Yet again, there are studies suggesting that retirement has virtually no implications at all for post-retirement wellbeing (Crowley, 1985; Warr et al., 2004; Luhmann et al., 2012).

Still, many studies on retirement adjustment rely on cross-sectional designs, comparing differences in quality of life between workers and retirees (e.g. Herzog et al., 1991; Midanik et al., 1995; Drentea, 2002). However, these kinds of data do not allow us to observe the intra-individual changes in wellbeing during the retirement transition (Wang, 2007). It is therefore necessary to adopt a longitudinal design in studying individuals' variation in wellbeing. Indeed, dynamic, longitudinal analyses can capture the process of moving from a job to retirement and can clarify the evolving consequences of this transition (Kim and Moen, 2001).

The major theoretical perspectives that have been applied as frameworks to study this heterogeneity in retirement adjustment include role theory and continuity theory (Wang et al., 2011). Both theories reason about the function that social roles - both working and extra-working roles - play in defining the identity of the individual. Coming to different conclusions, both theories address the consequences that losing a role can have for a person's adaptation and wellbeing. These theories have often been integrated with a lifecourse approach, which allows us to study retirement as a transition inserted in a lifelong process and not as a result of an isolated time-point. All these perspectives could be seen as complementary rather than contradictory because they focus on different aspects of the retirement adaptation process (Van Solinge, 2015). 


\section{Role theory}

Role theory has been often used as a framework for understanding retirement adjustment and, in particular, post-retirement psychological wellbeing. This theory suggests that some socially and personally relevant roles are important to building self-identity (Moen et al., 2000; Petters and Asuquo, 2008). They can emerge through relationships with neighbours, through work activities, through the family and so on. Therefore, society is structured around various roles, which prescribe norms and expectations for both behaviours and attitudes (Richardson and Kilty, 1991). Individual differences in adaptation to role changes can be understood by examining variations in different life transitions.

Since leaving the workforce requires a change of roles and activities, this approach can be applied to the retirement process as well. Therefore, retirement is seen as a transition that involves an expansion, redefinition and change of roles. Differences in post-retirement wellbeing can thus be attributed to an individual's ability to react to those changes.

The influence that the loss of role has on individual psychological wellbeing depends on the importance of that role during the lifecourse and the possibility of finding other satisfactory replacement roles (Carter and Cook, 1995). In fact, insofar as a person is strongly committed to a particular role, feelings of self-esteem tend to be associated with the ability to perform that role effectively (Ashforth, 2001).

Role theorists argue that the 'rolelessness' - or a bad adaptation to the new role of pensioner - can cause people to feel unhappy, anxious or depressed. This dynamic can lead to low levels of wellbeing in the post-retirement period (Riley and Riley, 1994), and life after retirement could be perceived as less satisfying than life before that transition. Indeed, researchers have found evidence that role loss is associated with decreased life satisfaction (Fry, 1992) and it is linked to poorer adjustment (Van Solinge and Henkens, 2008) as well as elevated levels of stress, depression and anxiety (Moen et al., 1992; Adams et al., 2002). In general, work and employment relationships are considered an important source of identity, and their loss could have negative consequences on the wellbeing of the individual, also in accordance with the level of development of the other life spheres (Jæger and Holm, 2004).

\section{Continuity theory}

The continuity theory, proposed by Atchley (1971), supports the idea that work is not as crucial for our self-concept and identity as role theory implies. We tend to form our identity from multiple sources and roles. Even though job-related roles and activities are lost, other sources for building one's identity remain, such as family and non-work-related social networks. Then, the coherence of life patterns over time is emphasised: there is a continuity of the self-identity in the retirement transition, and this continuity contributes to the adaptation of the individual to retirement (Atchley, 1999). Rather than focusing on retirement as a process of loss of role, continuity theorists describe it as an opportunity to maintain social relationships and life patterns. Therefore, this theory argues that there should be no significant decline in psychological wellbeing when people move from work to retirement unless they have difficulties in maintaining their general life patterns (Wang et al., 2011). The theoretical assumption of the continuity theory is that individuals are regularly guided by 
existing internal mental frameworks, which make them prone to maintaining similar patterns of behaviours across time (Atchley, 1999). Individuals tend to preserve their social roles, lifestyles and values even when they retire (Atchley, 1976, 1993). In other words, the most common pattern of adjustment in retirement is maintaining the same lifestyle patterns developed prior to retirement (Wang, 2007). Dealing with change, ageing adults select alternatives that are coherent with their prior social identities and activities, sustaining the sense of self.

Atchley (1976) has also proposed a model for describing the retirement adjustment process. The first period of retirement - he claims - could be related to the so-called honeymoon, an increase in wellbeing, due to the experience of the new freedom. This period is then followed by what the author calls disenchantment, as people have to cope with daily life in retirement and new problems. Afterwards, retired people experience a sort of reorientation in which they need to learn how to cope with the realistic opportunities and demands of this stage of life. This period in turn leads to a phase of moderate stability. Finally, in the last stage, called termination, people could experience a loss of independence due to more marked age-related changes (Henning et al., 2016).

It should be noted that continuity theory does not exclude the existence of psychological stress caused by role exit and role transitions. Instead, it underlines that maintaining continuity is essential for retirees to preserve their psychological wellbeing. Therefore, individuals who maintain their lifestyle or activities through retirement or who view retirement as a realisation of a prior goal should not experience significant decline of psychological wellbeing during the retirement transition (Wang, 2007). Moreover, retirement may offer the opportunity to spend more time in the roles of friend and family member (Reitzes et al., 1994), which offer psychological continuity to retirees. These family and community roles may provide social relationships that enable social integration and increases wellbeing among adults (Reitzes and Mutran, 2004). The continuity theory further argues that retirement may offer relief from job pressure and performance expectations. This dynamic may improve psychological wellbeing. In short, continuity is so important in this perspective, since pre-retirement priorities and activities have more impact on later life than retirement itself.

\section{Lifecourse theory}

The lifecourse perspective (Elder, 1995)) ; Elder and Johnson, 2003) focuses on important points for the comprehension of post-retirement wellbeing: transitions and trajectories; contextual embeddedness; and the interdependence of spheres of life and timing of transitions (Szinovacz, 2003). Transitions refer to changes of state over time (e.g. from employment to retirement) and trajectories refer to the development of life in relatively stable states (e.g. employment history). The concept of contextual embeddedness implies that the experience of life transitions and developmental trajectories depends on the specific circumstances in which the transition occurs (e.g. health, career trajectories, social network, etc.), and the principle of the interdependence of life spheres emphasises that experiences in one sphere of life (e.g. retirement life) influence, and are influenced by, experiences in other spheres of life (e.g. marital or working life) (Wang, 2007). 
A lifecourse perspective emphasises that retirement is one transition in the context of a lifetime of employment (Quick and Moen, 1998), and stresses how individuals construct their life roles, including their careers, framed within the environment and other life domains. In general, the importance of earlier life experiences for explaining behaviour later in life is underlined (Settersten, 2003: $15-45)$.

In the existing literature, the influence of the working history on retirement adjustment has often been investigated through variables related to employment observed at a precise time-point (for instance, the job from which the individual retired; e.g. Atchley, 1982; Newman et al., 1982), providing only a snapshot of the work history itself (Quick and Moen, 1998). Only a few studies have focused on the cumulative process over the lifecourse by examining lifecourse determinants of late-life outcomes (Ponomarenko, 2016). However, they did not specifically focus on women's wellbeing after retirement. This gap in the literature is remarkable, given that work experiences accumulated over the lifecourse could be crucial in shaping the consequences of later-life transitions (Damman et al., 2011; Bennett and Moehring, 2015). Indeed, the lifecourse principle of agency within the structure (Settersten, 2003) postulates that older adults make choices and take actions within the opportunities and restrictions of their broader social worlds, influenced by various life domains and personal histories.

Previous labour market experiences vary to a great extent concerning, for instance, the number of years spent in employment, the occupational status achieved and experience of discontinuity in career paths (e.g. Wahrendorf et al., 2017). The accumulation of specific labour market experiences creates opportunities and limitations that drive older adults in their decisions and adaptation after retirement (Dingemans and Möhring, 2019). Career development is therefore seen as a lifelong process, in which other life roles are taken into account, allowing retirement decisions to be considered in the context of other relevant identities (spouse, grandparent, etc.) Hence, retirement is also seen as a life transition in an ongoing trajectory and the retirement experience as influenced by previous life events such as job-related variables and family-related variables (Wang et al., 2008; Von Bonsdorff et al., 2009).

\section{The importance of women's employment history}

As we have previously seen, the increase in women's labour force participation has contributed to the changing nature of retirement, as the number of women experiencing this later-life transition has increased and continues to do so (Slevin and Wingrove, 1995). Several researchers have shown that the retirement transition can no longer be perceived as a 'male-only' event (Price and Nesteruk, 2010), and have highlighted the need to recognise the unique context in which women retire (Calasanti, 1993; Price, 1998; Richardson, 1999; Price and Nesteruk, 2010). It has been also argued that traditional retirement models are unsuitable for women, who are more likely to have an uneven working live than men (Richardson, 1999; Simmons and Betschild, 2001; Byles et al., 2013). Indeed, there are several reasons for examining women's retirement separate from men's retirement (Price and Nesteruk, 2010). These include the difference in how 
women experience retirement, the different way in which they combine work and family responsibilities, the financial instability of female retirees, and their greater longevity, which extends their retirement period compared to that of men (Price, 1998; Quick and Moen, 1998; Price and Nesteruk, 2010). Furthermore, the different occupational trajectories of women and men could influence their retirement process differently and this could affect an individual's orientation and satisfaction with life during retirement (Calasanti, 1996).

The literature about males' retirement adjustment process highlights the importance of work for men's psychological wellbeing (Cinamon and Rich, 2002), suggesting that men with long periods of non-employment have more depressive symptoms later on compared to men with continuous employment (Wahrendorf et al., 2013). It thus may be assumed that continuous employment promotes opportunities of meeting psychosocial and economic needs, while precarious and unstable careers may be accompanied by the recurrent experience of psychosocial stress, with adverse consequences for health and wellbeing (Chandola et al., 2006; Wahrendorf et al., 2013).

As for women, they are more likely to be care-givers for younger and older family members, and they often adapt their work behaviour to satisfy this responsibility (Hatch and Thompson, 1992; O'Rand et al., 1992; Pienta, 1999). These discontinuities in women's labour force participation lead to some negative consequences, such as having fewer opportunities to develop skills, increase knowledge or move up the organisational hierarchy. As a result, women may be less likely to receive promotions, accumulate pension credits or be in jobs with the most remunerated pension plans (Quick and Moen, 1998). Several of these consequences could have an impact on retirement adjustment.

Two main arguments can be found in the literature regarding the role of gender in the retirement adjustment process (Damman et al., 2015). On the one hand, women might have fewer difficulties adjusting to the loss of the social dimensions of work than men, as that they have more experience in terms of role transitions and career breaks, and may be more prone to perceive the family role as their main role (Damman et al., 2015). Women are more likely to decrease their engagement in the labour market or even leave it when they have children. Consequently, having already taken advantage of alternative roles, the transition to retirement may be easier because they are often less attached to the labour market. Alternative roles should moderate the negative influence of retirement on the subjective wellbeing dimension (Ryser and Wernli, 2017). On the other hand, it can be assumed that women face financial difficulties when they leave the job role, as they may be economically vulnerable due to their interrupted working careers or low-paid occupations (Damman et al., 2015). In this regard, there is evidence that females have more negative attitudes towards retirement than males do, and that retirement is more likely to be linked with greater loneliness and depression for females than for males (Van Solinge and Henkens, 2005; Fadila and Alam, 2016).

To conclude: since working careers, developed and combined with family histories, have important consequences for women's later-life characteristics (e.g. Pienta et al., 1994), the entire employment history could be considered to be an important factor in explaining the effect of the retirement transition on subjective wellbeing. More specifically, working history is interconnected with family responsibilities 
and, as such, it becomes a fundamental factor influencing the attachment to the labour market and to the role of 'worker'.

\section{Research questions}

Despite the wealth of research investigating the relationship between life events and subjective wellbeing, there remains a limited understanding regarding the consequences of retirement on subjective wellbeing (Horner, 2014) and its relationship with working lifecourses. Previous studies have often relied on repeated cross-sectional data that cover only a time-point in women's lives, even though work and care-giving roles vary over time (Moen and Chermack, 2005). Moreover, relatively little research has focused specifically on the relationship between women's working history and their subjective wellbeing - especially in the context of retirement transition.

Both cross-sectional and longitudinal studies show very mixed results regarding this theme. In fact, on the one hand, we have evidence that supports an increase in wellbeing after retirement (e.g. Reitzes et al., 1996; Isaksson and Johansson, 2000; Latif, 2011; Wetzel et al., 2016; Ponomarenko et al., 2019). Several previous studies have shown that retirement may lead to a positive overall experience by offering opportunities for role enrichment (Wang, 2007), leisure (Pinquart and Schindler, 2009) and civic engagement (Kaskie et al., 2008). These are all factors that have been shown to be positively linked to levels of wellbeing (Hershey and Henkens, 2014).

On the other hand, some results go in the opposite direction, pointing to negative effects of the retirement transition (e.g. Richardson and Kilty, 1991; Dave et al., 2008). For new retirees, the experience of encountering substantial life changes could lead to a decreased sense of self-esteem (Ashforth, 2001), anxiety and depression, and to a lower general level of subjective wellbeing (Hershey and Henkens, 2014). There are also studies that find no effects (or continuity) of retirement transition on wellbeing (e.g. Crowley, 1985; Mayring, 2000; Kim and Moen, 2002; Warr et al., 2004; Szinovacz and Davey, 2006; Luhmann et al., 2012) and studies that find beneficial effects of retirement in the short term, followed by a long-term decline in wellbeing (Horner, 2014), and that also point to differences relating to education and social status (Wetzel et al., 2016). Finally, there are studies that link the characteristics of working lifecourse with the retirement effects on wellbeing that have found that persons who have been involuntarily unemployed experience a significant increase in wellbeing after retirement (e.g. Hetschko et al., 2014; Ponomarenko et al., 2019), whereas economically inactive persons do not show the same increase (Ponomarenko et al., 2019).

Due to the inconsistency of the results obtained by the existing literature and the lack of a solid theoretical framework regarding the association between women's working history and changes in psychological wellbeing through retirement, I find it very difficult to formulate verifiable hypotheses. Therefore, this research has an explorative intention and seeks to integrate the two main theories on retirement adaptation - role and continuity theory - with a lifecourse approach. I consider the entire working lifecourse of European women (from 20 to 50 years of age) and examine (a) whether the transition to retirement affects female subjective wellbeing and (b) whether a possible change in subjective wellbeing differs according to the structure of the working career. 


\section{Data and methods}

\section{Data}

I use data from SHARE which is a multi-disciplinary and cross-national panel database of micro data on health, socio-economic status, and social and family networks of individuals aged 50 or older. Specifically, for the sequence analysis, I use the third and seventh waves, SHARELIFE, which were collected in 2008/ 2009 and in 2017. SHARELIFE provides detailed retrospective information about individual work-family trajectories from early adulthood until retirement. For the regression analysis and the sample selection I used the regular waves of the survey (Waves 1, 2, 4, 5 and 6) and the regular part of Wave 7. Indeed, Wave 7 contains the retrospective questionnaire for all respondents who did not participate in Wave 3 (first SHARELIFE questionnaire), as well as a panel questionnaire for all respondents who had already answered the first SHARELIFE interview and for the new respondents entering the survey. Brugiavini et al. (2019) transformed the employment history variables (combining Waves 3 and 7) into a long data format, the Job Episodes Panel, which includes all relevant information on employment history.

\section{Sample selection}

Sequence analysis and regression models have been applied to the same sample of individuals, which I selected as the population of interest in this study. I selected women who were working or were unemployed the first time they were observed in the panel (I therefore excluded women who had already retired or who were permanently sick or disabled) and who made the transition to retirement during the observation period. When constructing the sample, the observations reporting more than one retirement transition or returning to the labour market after retirement were censored (right-censoring). Indeed, the aim of the paper is to focus on the first retirement transition. Moreover, I selected only individuals with no missing information on the variables used in the models and I excluded respondents with fewer than five recorded years in the labour market. In fact, persons who were inactive during most of their life are often excluded from the population of interest because the notion of retirement presupposes prior work (Radl, 2014). Since SHARELIFE does not provide current information but only retrospective events, the sample is constructed by, first, identifying the population of interest in the regular panel waves. Then, information about employment and family history is added to this sample. The final sample is composed of 2,877 respondents (with no missing information on any the variables used) from 11 European countries (Austria, Belgium, Denmark, France, Germany, Italy, The Netherlands, Poland, Spain, Sweden and Switzerland).

\section{Methods}

The empirical analyses are developed in two steps: in the first part, I performed sequence analysis to construct the individual working sequences and to explore the existence of similar patterns of career. In the second part, I related the career 
clusters with the variation in wellbeing before and after the retirement transition, running different fixed effects regression models on the different sub-samples defined by each specific career cluster. In a first step, I estimated a fixed effects regression model including only the main independent variable, which accounts for the years before and after retirement, to assess how the association between retirement transition and life satisfaction varies across the different clusters/subsamples, as defined by their working trajectories. I aggregate the independent variable in five categories (two or more years before retirement; one year before; retirement year; one year retired; two or more years retired) and the analysis is divided by career trajectory. In a second step, I introduced the relevant covariates into the models.

\section{Sequence analysis}

The use of sequence analysis to study lifecourse has been earning growing attention; it has been widely recognised as a valuable toolbox for investigating life trajectories (Abbott and Hrycak, 1990; Abbott and Tsay, 2000; Billari and Piccarreta, 2005). Even if this method is mostly explorative, it makes it possible to trace lifecourses entirely, investigating dynamic processes that are difficult to understand with other methods in lifecourse research (like event history analysis) (Ponomarenko, 2016).

Indeed, sequence analysis takes into account the whole career and makes it possible to treat data in a holistic way. Moreover, it permits a reduction of complexity and the creation of order from a large variety of individual sequences (Hansen and Lorentzen, 2019). Indeed, the main purpose of this technique is to detect the order, or patterns, in a sequence of events or states that are observed for a given set of actors (Cornwell, 2015).

Sequence analysis normally proceeds in different steps: first, the data are coded using an alphabet of states that is useful to construct the sequences, then a cost matrix is defined and an algorithm is applied, resulting in a matrix of distances between all pairs of sequences. This matrix is then analysed with a data reduction method like cluster analysis (Abbott and Tsay, 2000). The difference between a given pair of sequences is determined by quantifying the transformations needed to turn one sequence into another sequence (Gabadinho et al., 2011; Calvo et al., 2018). There are several approaches to this calculation. Some of them consider the order of the event to be more important than the timing; others consider timing to be more important than order (Lesnard, 2010). I chose the optimal matching approach. Optimal matching analysis is a procedure that counts the 'costs' needed to transform sequence A into sequence B and vice versa by counting the minimum number of transformations needed. Two types of operation are possible: substitution and insertion/deletion. The dissimilarities are calculated by comparing each sequence with each other (Cornwell, 2015). To explore the robustness of the findings, I tried several cost specifications and chose the above-mentioned because it generated the most distinct cluster specification indicated by several cluster cut-off criteria. ${ }^{1}$

It is then possible to perform a cluster analysis on the resulting distance matrix, which allows homogeneous groups of sequences to be created, which, taken together, represent types of trajectories (Gauthier et al., 2010). For this purpose, I use Ward's cluster analysis (Ward, 1963). To determine the most appropriate number of clusters, I considered several cluster cut-off criteria, including the 
Average Silhouette Width and Point Biserial Correlation ${ }^{2}$ (Hennig and Liao, 2013; Studer, 2013) that identify the most discriminant number of groups. The Average Silhouette Width ranges between 0 and 1 . Higher values indicate a more discriminant grouping. Values greater than 0.25 suggest that there is a meaningful structure in the data that is captured in the respective grouping (Studer, 2013). ${ }^{3}$

\section{Status alphabet}

For the construction of the sequences, the respondents enter into the analysis at 20 years of age and they are followed until they are 50 years of age (I chose these age cut-off criteria to start observing people once they leave the education system and finish observing them when the transition to retirement normally becomes possible). For the current analysis, five distinct and mutually exclusive work statuses were defined every year, for a total of 31 years. The variables used to define the status alphabet collect the information about the yearly work status and hours worked (part-time or full-time). Therefore, the status alphabet is coded into these categories: in education, part-time work, full-time work, unemployed/inactive and retired.

\section{Panel regression analysis}

The panel nature of SHARE is extremely valuable for a study on the effects of retirement transition characteristics on wellbeing. The fixed effects regression model is the most common technique to analyse panel data. This model makes it possible to eliminate the effect of potential unobserved factors that remain constant over time. The logic behind this is to express the change in the outcome variable as a function of the changes recorded in the variables that vary over time. The factors that remain constant are eliminated. Hence, I used fixed effects linear regression models to examine the extent to which retirement transition is associated with changes in psychological wellbeing.

This study takes advantage of the longitudinal nature of SHARE to calculate the change in wellbeing between the first respondent observation and various later time-points. Indeed, I have information on several measures/dimensions of respondents' wellbeing: (a) before the retirement transition (from five years to one year before retirement, depending on when the individual makes the transition to retirement); (b) the year of the retirement transition; and (c) some years after retirement, until the respondent's last observation. The sample is unbalanced: some individuals are observed only until retirement, others until one year after retirement, others until two, three or four years after the transition. In this paper, models were estimated on the different sub-samples defined by each specific career cluster.

\section{Definition of key variables}

\section{Life satisfaction}

In this analysis, subjective wellbeing is the dependent variable and is measured by life satisfaction on a $0-10$ scale with 10 being the most positive satisfaction with life. Shin and Johnson (1978) define life satisfaction as a global evaluation of a person's quality of life based on his or her criteria. It is important to underline that these criteria are set by the individual for him- or herself; they are not imposed externally. For example, although health, income, social network and so on may be desirable, 
individuals may give them differing levels of importance. For this reason, the life satisfaction scale generally asks the person for the overall evaluation of his or her life, rather than summing up satisfaction with specific sectors (Diener et al., 1985). It is a measure of subjective wellbeing that evaluates life as whole rather than current feelings and, therefore, integrates long-term developments (Diener, 2009). This aspect makes it extremely suitable for studying long-term consequences of life trajectories (Poromanenko, 2016).

\section{Main independent variable: retirement transition}

Respondents are asked to best describe their current employment situation from a list of 'retired, employed, self-employed and unemployed'. Respondents are classified as being retired if they report that they are retired in answer to this question. The percentage of people who are retired increases steadily across each wave of data between 2004/2005 (Wave 1, in which I selected only employed or unemployed people) and 2017 (Wave 7, in which the whole sample is retired) (Figure 1).

A variable has been constructed in order to measure retirement transition, i.e. considering time before and after the year of retirement. ${ }^{4}$ It is a 'time variable', constructed from the six waves of SHARE as illustrated in Figure 2. This time variable represents the period before retirement (coded -5 to -1 ), the transition to retirement (coded 0 for the year of retirement) and the period after retirement (coded 14) for all respondents included in the sample. Since the sample is not balanced, not all the respondents are present from Time -5 to Time 4 .

\section{Covariates}

The literature on wellbeing has found a large variety of demographic, economic, familial and social network-related variables to be significant in predicting levels of wellbeing and their variation (Herzog and Rodgers, 1981; Kim and Moen, 2001). In this analysis, I include a number of these factors - of course excluding time-invariant ones - as control variables when analysing the effects of retirement on wellbeing. The distribution of the variables used in the analysis and the main characteristics of the analytical sample are shown in Table 1.

First of all, poor health has been found to have significant negative effects on mental wellbeing among retired people (Midanik et al., 1995; Dwyer and Mitchell, 1999). People in good health are more likely to make successful retirement adjustments than those in poor health (De Vaus and Wells, 2004; Bender and Jivan, 2005). Healthy people may engage in a greater range of activities and opportunities for access to social support than those who are less healthy, thereby helping to increase quality of life in retirement (Heybroek et al., 2015). Therefore, I included in the analysis the presence of limitations with instrumental activities of daily living as a categorical variable (no limitations, one or more limitations) and also the selfperceived health variable (excellent, very good, good, fair, poor). Family transitions, in later life too, have also been found to be associated with varying retirement experiences (Szinovacz and Ekerdt, 1995) and with changes in subjective wellbeing. First, marital status has been shown to be related to wellbeing among old people (Barer, 1994; Hilbourne, 1999; Kim and Moen, 2001), as well as in the general population (Haring-Hidore et al., 1985; Kurdek, 1991). Family relationships can provide social and psychological benefits, suggesting that people who are in a 


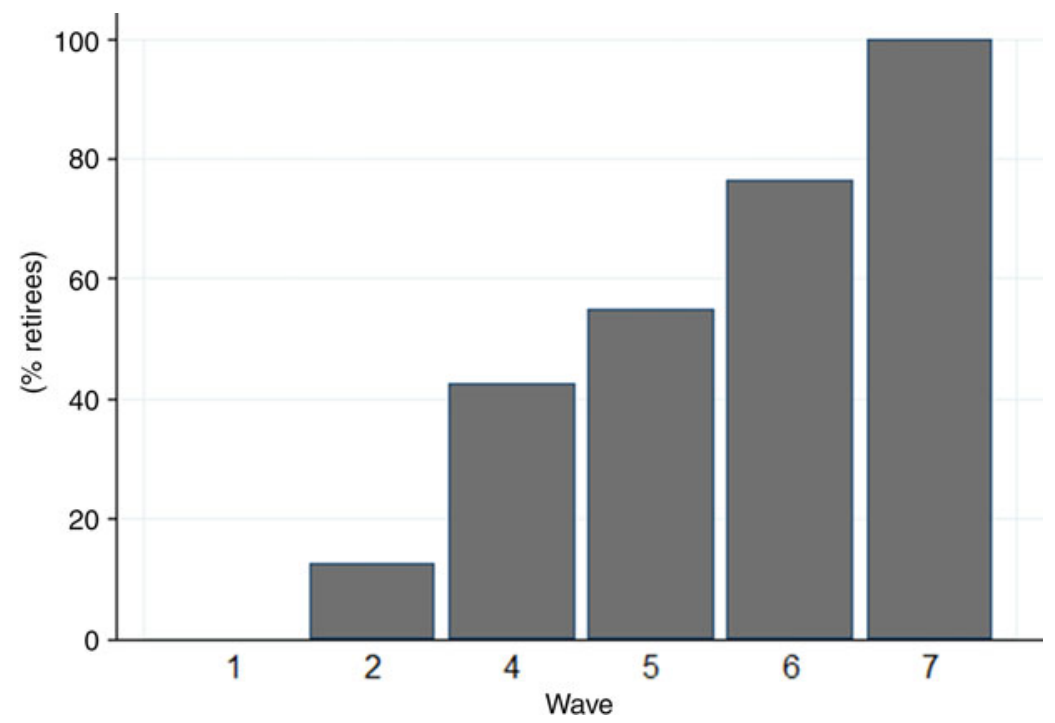

Figure 1. Percentage of retired respondents at each wave, 2006/2007 to 2017.

\begin{tabular}{lcccccccccc}
\hline Retired & 0 & 0 & 0 & 0 & 0 & 1 & 1 & 1 & 1 & 1 \\
\hline Time & -5 & -4 & -3 & -2 & -1 & 0 & 1 & 2 & 3 & 4 \\
\hline Retired in W2 & & & & & W1 & W2 & W4 & W5 & W6 & W7 \\
Retired in W4 & & & & W1 & W2 & W4 & W5 & W6 & W7 & W7 \\
Retired in W5 & & & W1 & W2 & W4 & W5 & W6 & W7 & & \\
Retired in W6 & & W1 & W2 & W4 & W5 & W6 & W7 & & & \\
Retired in W7 & W1 & W2 & W4 & W5 & W6 & W7 & & & & \\
\hline
\end{tabular}

Figure 2. Specification of time variables. Note: W: Wave.

relationship may report a higher level of life satisfaction in retirement than those who are divorced, separated, widowed or single (Reitzes et al., 1996; Szinovacz, 2003). People living without a partner are less likely to have strong networks of support in retirement and may be at risk of loneliness (Wolcott, 1998; Heybroek et al., 2015). Hence, in this analysis, I controlled for the effect of change in civil status, looking at co-habitation and coding it into three categories: (a) if the respondent is living with a partner/spouse, (b) if the respondent is not living with a partner/ spouse, and (c) if the respondent becomes a widow. These categories include women who are (were) in a co-habiting relationship without distinction between married and unmarried. I controlled also for the effect of becoming a grandparent (not having grandchildren, having grandchildren). Furthermore, former studies suggest that changes in the economic situation are also important in explaining adaptation and wellbeing (George, 1992; Holden and Kuo, 1996); other socioeconomic factors such as social class and level of education are also significant predictors of wellbeing among retired people (Dahl and Birkelund, 1997). In order to 
Table 1. Descriptive statistics (observed the year before retirement)

\begin{tabular}{|c|c|}
\hline Variables & $\%$ \\
\hline \multicolumn{2}{|l|}{ Educational level: } \\
\hline ISCED 0 and 1 & 11.8 \\
\hline ISCED 2 & 15.8 \\
\hline ISCED 3 and 4 & 39.1 \\
\hline ISCED 5 and 6 & 33.3 \\
\hline \multicolumn{2}{|l|}{ Marital status: } \\
\hline Never married & 6.4 \\
\hline With a partner & 70.5 \\
\hline Separated/divorced & 15.3 \\
\hline Widow & 7.8 \\
\hline \multicolumn{2}{|l|}{ Number of children: } \\
\hline None & 9.6 \\
\hline One & 18.1 \\
\hline Two or more & 72.3 \\
\hline \multicolumn{2}{|l|}{ Have grandchildren: } \\
\hline Yes & 63.4 \\
\hline \multicolumn{2}{|l|}{ IADL limitations: } \\
\hline One or more & 6.7 \\
\hline \multicolumn{2}{|l|}{ Self-perceived health: } \\
\hline Excellent & 14.6 \\
\hline Very good & 27.3 \\
\hline Good & 38.3 \\
\hline Fair & 16.8 \\
\hline Poor & 3.1 \\
\hline \multicolumn{2}{|c|}{ Household able to make ends meet: } \\
\hline With great difficulty & 4.7 \\
\hline With some difficulty & 16.2 \\
\hline Fairly easily & 32.3 \\
\hline Easily & 46.9 \\
\hline Total & 100 \\
\hline Mean age (SD) & $60.1(0.1)$ \\
\hline $\mathrm{N}$ & 2,877 \\
\hline
\end{tabular}

Notes: ISCED: International Standard Classification of Education. IADL: instrumental activities of daily living. SD: standard deviation. 
account for the economic situation, I controlled for a measure that asks the respondent whether his or her household has the ability to make ends meet. This variable ranges from 1 ('with great difficulty') to 4 ('easily'). As a consequence of using fixed effects, I do not need to specify time-invariant variables such as gender, country of residence or education level.

\section{Results}

\section{Sequence analysis and working history}

The cluster cut-off criteria suggest seven clusters as the best grouping. Figure 3 illustrates the groups of working trajectories as state distribution plots from 20 to 50 years of age (Gabadinho et al., 2011). State distribution plots show, at each age, the distribution of employment statuses. Unlike sequence index plots, where individual sequences are chronologically ordered, state distribution plots reduce individual information to general proportions and gather individual sequences into more holistic and abstract clusters, facilitating interpretation (Ponomarenko, 2016; Calvo et al., 2018).

The first cluster, named 'Full-time employed', is the largest group and accounts for 45 per cent of the final sample. This group represents the standard model of continuous full-time employment. The second cluster, 'Mixed', accounts for 8 per cent of the sample. Here, women have had mainly a full-time working lifecourse, interspersed with many years of part-time work and some periods of inactivity, particularly in the middle of the observational period. The third cluster is called 'Late entry and full-time employed' and accounts for 8 per cent of the sample. Women in this group enter the labour market around 25-28 years of age because they stay longer in education - with a full-time job, and then they have a continuous career. The fourth group is the 'Long-term inactivity', which accounts for 10 per cent of the sample. Women in this group enter the labour market with a full-time job and exit around 25-30 years of age. Around 45 years of age, some of them re-enter the workforce again with a part-time or full-time job. The fifth cluster is called 'Mid-life discontinuity and full-time'. This course is followed by 5 per cent of the women in the sample and it is characterised by a full-time trajectory interrupted by periods of inactivity from 25 to 35 years of age. The sixth group, the 'Mid-life discontinuity and part-time' cluster, accounts for 11 per cent of the sample. Like in the fifth cluster, women in this group have a career interruption at around 25 years of age, but re-enter the labour market (around 10 years later) with a part-time job instead of a full-time one. The last cluster is called 'Part-time employed' and is followed by 12 per cent of the sample. Women in this group follow a continuous part-time trajectory.

Table 2 reports the main sociodemographic characteristics of each of the subsamples defined by the work trajectory, i.e. clusters. Across the clusters there are large differences in the distribution of the educational level and the number of children. In particular, the woman educated to higher levels (International Standard Classification of Education (ISCED) 5 and 6) are prevalent in clusters 1, 3 and 7, and those receiving a lower level of education (ISCED 0 and 1) are prevalent in clusters 4 and 5. Regarding the number of children, the percentage of women 
(1) Full-time employed

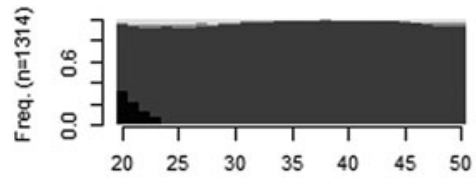

(3) Late entry and Full-time employed

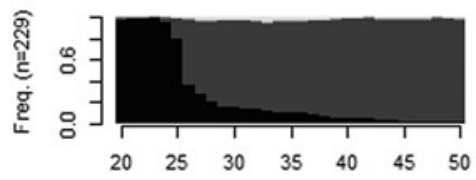

(5) Mid-life disc. and Full-time

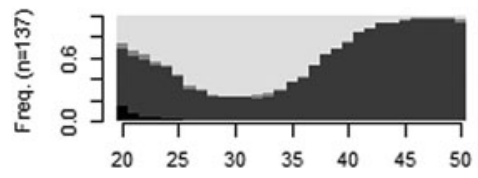

(7) Part-time

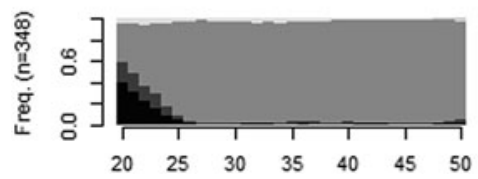

(2) Mixed

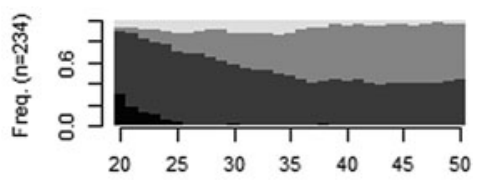

(4) Long-term inactivity

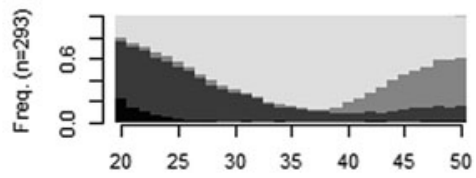

(6) Mid-life disc. and Part-time

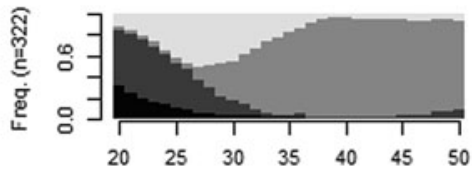

Figure 3. Seven-cluster solution. Employment history (20-50 years of age).

Notes: Freq.: frequency. disc.: discontinuity. OLM.: out of the labour market.

with two or more children is higher in groups with an atypical or discontinuous trajectory compared to the continuous and full-time pathways (clusters 1 and 3).

\section{Fixed effects regression models}

Figure 4 shows the result of the fixed effects regression model including only the main independent variable. It accounts for the years before and after retirement, to assess how the association between retirement transition and life satisfaction varies across the different clusters/sub-samples, as defined by their working trajectories.

Looking at the different working trajectories, we notice that the pathways 7 (part-time employed) and 6 (mid-life discontinuity and part-time) have a higher general level of wellbeing than the other trajectories. The greatest change in the level of wellbeing between the years before retirement and the retirement year is shown by groups 2, 4 and 5, which manifest an increasing trend in life satisfaction starting one or two years before the transition to retirement. For groups 2 and 5, we can notice a decline in life satisfaction, starting in the year of the transition. In the case of group 4 (long-term discontinuity), the increase continues until one year 
Table 2. Descriptive information of seven groups of working trajectories (observed the year before retirement)

\begin{tabular}{|c|c|c|c|c|c|c|c|}
\hline & $(1)$ & $(2)$ & (3) & (4) & (5) & (6) & (7) \\
\hline & Full-time & Mixed & $\begin{array}{l}\text { Late entry and } \\
\text { full-time }\end{array}$ & $\begin{array}{l}\text { Long-term } \\
\text { discontinuity }\end{array}$ & $\begin{array}{l}\text { Mid-life discontinuity } \\
\text { and full-time }\end{array}$ & $\begin{array}{l}\text { Mid-life discontinuity } \\
\text { and part-time }\end{array}$ & Part-time \\
\hline & \multicolumn{7}{|c|}{ Percentages } \\
\hline \multicolumn{8}{|l|}{ ISCED: } \\
\hline ISCED 0 and 1 & 12.1 & 11.5 & 1.7 & 19.8 & 19.7 & 11.8 & 7.8 \\
\hline ISCED 2 & 15.7 & 17.5 & 2.6 & 23.9 & 18.2 & 19.9 & 12.4 \\
\hline ISCED 3 and 4 & 42.0 & 43.6 & 15.7 & 40.3 & 43.8 & 41.0 & 36.2 \\
\hline ISCED 5 and 6 & 30.3 & 27.3 & 79.9 & 16.4 & 18.2 & 27.3 & 43.7 \\
\hline \multicolumn{8}{|l|}{ Number of children: } \\
\hline None & 12.9 & 6.0 & 16.6 & 4.1 & 4.4 & 4.3 & 6.6 \\
\hline One & 22.2 & 18.8 & 15.7 & 5.3 & 12.4 & 15.2 & 16.1 \\
\hline Two or more & 64.9 & 75.2 & 67.7 & 87.4 & 83.2 & 80.4 & 77.3 \\
\hline \multicolumn{8}{|c|}{ Household able to make ends meet: } \\
\hline With great difficulty & 4.5 & 3.8 & 4.0 & 8.7 & 12.7 & 1.4 & 2.6 \\
\hline With some difficulty & 19.6 & 13.3 & 8.0 & 18.6 & 15.9 & 12.9 & 11.2 \\
\hline Fairly easily & 31.4 & 38.4 & 27.9 & 36.9 & 38.9 & 30.1 & 29.7 \\
\hline Easily & 44.5 & 44.5 & 60.2 & 35.8 & 32.5 & 55.6 & 56.4 \\
\hline Total & 100 & 100 & 100 & 100 & 100 & 100 & 100 \\
\hline
\end{tabular}


Table 2. (Continued.)

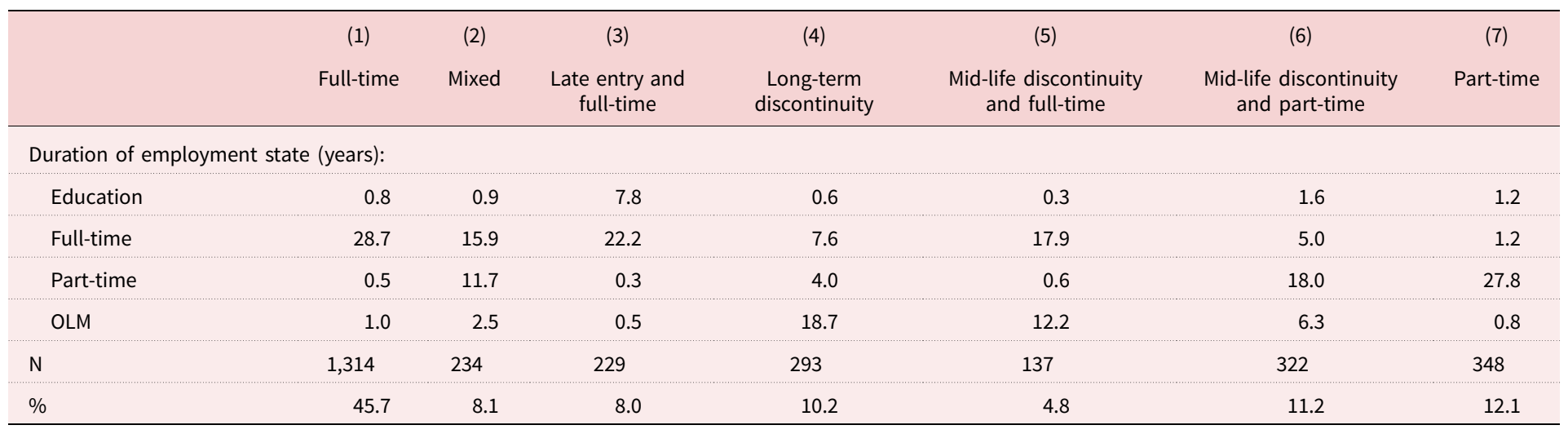

Notes: ISCED: International Standard Classification of Education. OLM: Out of the labour market. 

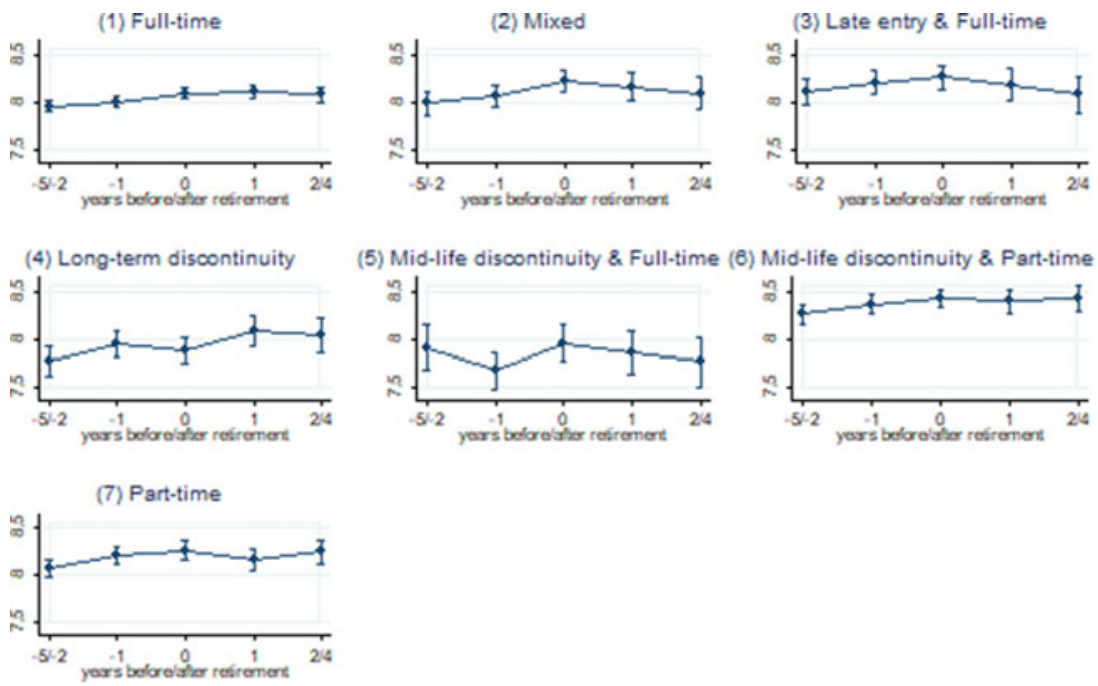

Figure 4. Predictive margins of retirement transition on life satisfaction by career trajectory, fixed effects without covariates (95\% confidence intervals are shown).

after retirement and then the level of life satisfaction remains fairly stable (there is only a slight decrease). As for the other clusters, the change in subjective wellbeing before and after retirement seems very minimal, particularly for group 1 (full-time employed), for which the displayed curve is almost flat.

Table 3 shows the results of the fixed effects regression models (with all the covariates), again divided by career trajectory. For cluster 1 (full-time employed), the effect of the independent variable is positive for each category compared with the reference one, which is two or more years before retirement. Nevertheless, the coefficients are very close to zero $(0.02,0.05,0.06,0.01)$ and are not statistically significant.

Group 2 (mixed) shows positive and quite large coefficients for all the categories compared to the reference one: there is an increase in life satisfaction as we move closer to the retirement transition and also once the women have retired. These results suggest a continuous increment in the level of life satisfaction (only two categories have statistically significant coefficients). The effects of retirement transition for cluster 3 (late entry and full-time employed) could indicate a continuous decrease in life satisfaction levels over time, however, the coefficients are not statistically significant. Cluster 4 (long-term discontinuity) manifests a positive increment in life satisfaction starting the year of retirement and it is continuous over the entire retirement process (the coefficient is significant only one year after retirement). The fifth pathway manifests a trend in life satisfaction that seems to increase in the year of retirement (0.7) and one year after retirement (0.6), but then decreases again for the category ' $2+$ years retired' $(-0.2)$. However, the coefficients are not statistically significant. The sixth group shows a similar pattern compared to the cluster just mentioned. About that, it should be added that the small sample size of some clusters (e.g. cluster 5) affects their statistical power and the statistical 
Table 3. Fixed effects regression model on life satisfaction scale divided by career trajectory

\begin{tabular}{|c|c|c|c|c|c|c|c|}
\hline & (1) & (2) & (3) & (4) & (5) & (6) & (7) \\
\hline & Full-time & Mixed & $\begin{array}{l}\text { Late entry } \\
\text { and } \\
\text { full-time }\end{array}$ & $\begin{array}{l}\text { Long-term } \\
\text { discontinuity }\end{array}$ & $\begin{array}{l}\text { Mid-life } \\
\text { discontinuity and } \\
\text { full-time }\end{array}$ & $\begin{array}{l}\text { Mid-life } \\
\text { discontinuity and } \\
\text { part-time }\end{array}$ & Part-time \\
\hline & \multicolumn{7}{|c|}{ Coefficients } \\
\hline \multicolumn{8}{|c|}{ Employment status (Ref. $2+$ years before retirement): } \\
\hline 1 year before retirement & 0.02 & 0.14 & -0.07 & 0.21 & -0.30 & -0.00 & $0.26^{\star *}$ \\
\hline 1 year retired & 0.06 & $0.45^{\star}$ & -0.21 & $0.56^{\star}$ & 0.06 & -0.03 & $0.48^{\star \star}$ \\
\hline $2+$ years retired & 0.00 & 0.53 & -0.34 & 0.57 & -0.02 & -0.09 & $0.78^{\star \star}$ \\
\hline $\mathrm{Age}^{2}$ & 0.00 & -0.00 & -0.00 & -0.00 & 0.00 & 0.00 & -0.00 \\
\hline Age & -0.06 & 0.11 & -0.19 & 0.05 & 0.15 & -0.02 & 0.12 \\
\hline Widow & -0.17 & 0.45 & $-1.04^{\star \star}$ & $-1.29^{\star \star \star}$ & -0.20 & -0.22 & $-0.53^{\star}$ \\
\hline \multicolumn{8}{|c|}{ Have grandchildren (Ref. No.): } \\
\hline Yes & 0.02 & -0.04 & 0.15 & -0.03 & -0.32 & -0.07 & 0.05 \\
\hline
\end{tabular}




\begin{tabular}{|c|c|c|c|c|c|c|c|}
\hline \multicolumn{8}{|l|}{ Health: } \\
\hline One or more IADL limitations & $-0.18^{\star}$ & -0.05 & 0.18 & -0.16 & $-0.80^{\star \star \star}$ & -0.10 & -0.05 \\
\hline \multicolumn{8}{|c|}{ Self-perceived health (Ref. Excellent): } \\
\hline Very good & -0.04 & -0.22 & -0.19 & -0.18 & -0.24 & -0.10 & -0.14 \\
\hline Good & $-0.20^{\star \star}$ & $-0.50^{\star \star \star}$ & -0.25 & -0.31 & $-0.49^{\star}$ & $-0.25^{\star}$ & $-0.22^{\star}$ \\
\hline Fair & $-0.43^{\star \star \star}$ & $-0.53^{\star \star}$ & -0.36 & $-0.51^{\star \star}$ & -0.34 & $-0.40^{\star \star}$ & $-0.43^{\star \star}$ \\
\hline Poor & $-1.06^{\star \star \star}$ & $-1.16^{\star \star \star}$ & $-1.61^{\star \star \star}$ & $-0.92^{\star}$ & $-1.31^{\star \star}$ & 0.17 & $-0.93^{\star \star \star}$ \\
\hline \multicolumn{8}{|l|}{ Income: } \\
\hline \multicolumn{8}{|c|}{ Ability to make ends meet (Ref. Fairly easily): } \\
\hline With great difficulty & $-0.48^{\star \star \star}$ & -0.10 & -0.46 & -0.21 & -0.11 & $-0.57^{\star}$ & 0.01 \\
\hline With some difficulty & -0.11 & $-0.32^{\star}$ & 0.07 & -0.18 & -0.08 & $-0.35^{\star \star}$ & -0.00 \\
\hline Easily & $0.12^{\star}$ & 0.03 & 0.07 & 0.24 & 0.06 & -0.02 & 0.03 \\
\hline $\mathrm{N}$ & 1,314 & 234 & 229 & 293 & 137 & 322 & 348 \\
\hline
\end{tabular}

Notes: Ref.: reference category. IADL: instrumental activities of daily living. Significance levels: ${ }^{\star} p<0.05,{ }^{\star \star} p<0.01,{ }^{\star \star \star} p<0.001$. 

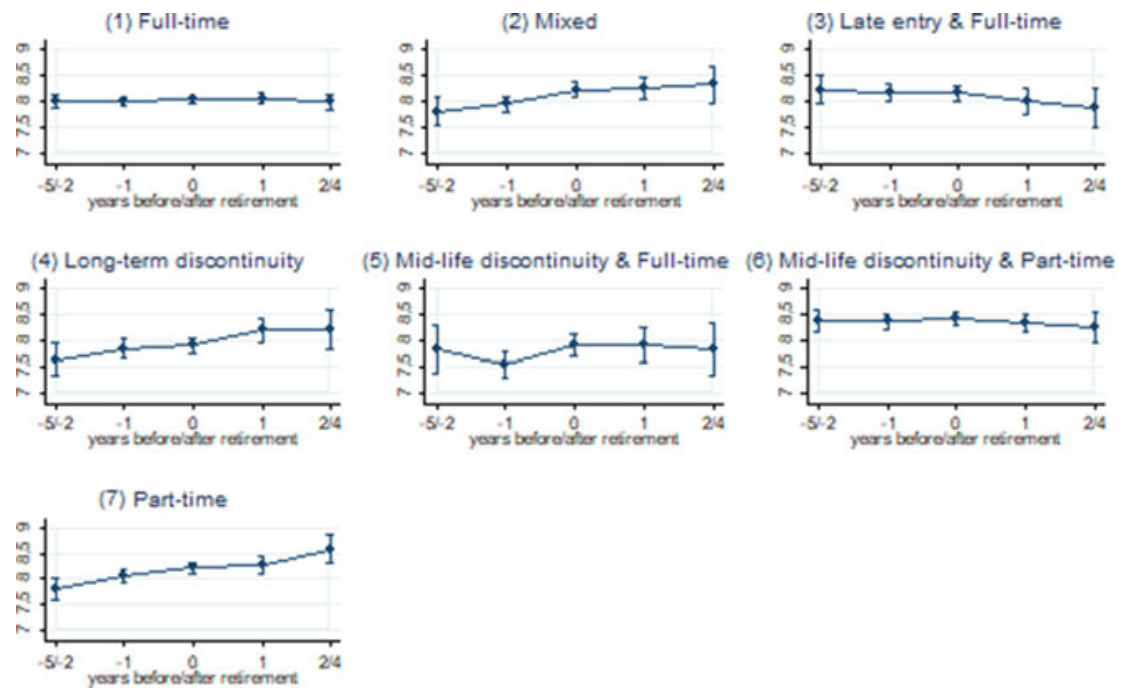

Figure 5. Predictive margins of retirement transition on life satisfaction by career trajectory $(95 \%$ confidence intervals are shown).

significance of the variables in the models. To conclude, cluster 7 (part-time employed) shows positive and significant coefficients: the level of life satisfaction increases continuously during and after the retirement transition.

Regarding the covariates, a worsening of health conditions leads to a decrease in the level of life satisfaction for all clusters. Furthermore, the results of the analyses indicate that, in general, the economic situation plays a role in determining the level of wellbeing: unsurprisingly, the shift to a difficult economic situation reduces the quality of life. The effect of the presence of family networks is different across the clusters considered. I find that becoming a grandparent seems to have an effect close to zero for some clusters but increases wellbeing for others; however, the coefficients are not statistically significant. Moreover, becoming a widow decreases the level of life satisfaction for many of the clusters (though it is significant only for the third, fourth and seventh groups).

Figure 5 shows linear predictions from the previous fixed effects models. Although, in some cases, the standard errors are large, these figures graphically confirm that being retired is associated with an increment in the level of life satisfaction for the second, fourth and seventh groups. Women in the fifth and sixth clusters, on the other hand, perceive a decrease in wellbeing starting from the retirement year. Those in the first clusters seem to perceive a sort of continuity in life satisfaction levels throughout the observation period. Finally, women in group 3 experience a continuous decline in their levels of life satisfaction that starts two or more years before retirement and greatly worsens during the year of the transition.

\section{Discussion}

With increasing female retirement across many Western societies, questions arise regarding the characteristics of retirement itself. While previous research has 
mainly focused on predictors proximal to the retirement transition, and on men, this paper investigates the consequences of retirement from paid work for the overall wellbeing of women, and, most importantly, how these consequences vary across women who have experienced contrasting paid-work career trajectories. Overall wellbeing is expressed by the life satisfaction indicator.

In line with the lifecourse theory (Elder et al., 2003), the results show that work histories, in addition to other well-known factors, such as a woman's health and economic situation, are crucial in explaining changes in wellbeing after retirement. In particular, some of the trajectories constituted of discontinuity or part-time periods (clusters 2, 4 and 7) showed a continuous increase in life satisfaction throughout the retirement transition. This result can be explained by the fact that women with this type of trajectory may have developed 'alternative' roles to that of 'worker' during their lifecourse to a greater extent than other women. For example, they could have exited the labour market, or have opted for a part-time job, in order to take care of children or other family responsibilities. In my case, the retirement transition not only seems to be easy but apparently increases wellbeing for women in those clusters. The rise in life satisfaction could be due to two dynamics: on the one hand, after the retirement transition, these women could have more time to spend with their family or for leisure. On the other hand, they no longer have to face great difficulties in reconciling work and family demands.

How do these findings fit into the existing literature? At the descriptive level of working histories, the findings - showing seven career pathways - are in line with previous results that indicated a great complexity of working pathways in the case of women (Macmillan, 2005; Widmer and Ritschard, 2009). However, in contrast to previous findings, the present results are not based on single-point measures or on specific characteristics of work history (e.g. involuntary job losses, frequent job changes or periods of unemployment) (Bambra and Eikemo, 2009; Wahrendorf et al., 2013; Wahrendorf, 2015). Rather, the focus was on entire working histories where five different work statuses were considered. With regard to the investigated associations between work histories and life satisfaction, the results supplement the previous findings, which argued that women who decreased their engagement in the labour market in some periods (such as those with part-time or discontinued careers) and have taken advantage of alternative roles experience an easy transition to retirement. Indeed, alternative roles should moderate the influence of retirement on the subjective wellbeing dimension (Ryser and Wernli, 2017). Again, other studies (e.g. Wahrendorf, 2015) suggested that the best quality of life was found among women with mixed histories (domestic work and employment) whilst women with regular histories (continued employment) had a lower quality of life (Wahrendorf, 2015). In my case, women with mixed or part-time histories benefit from the retirement transition in terms of subjective wellbeing. Moreover, the results partially support the continuity theory, according to which retirement may offer the opportunity to spend more time in the roles of friend and family member (Reitzes et al., 1994), offering psychological continuity to retirees. These family and community roles may provide social relationships that enable social integration and increase wellbeing among adults (Reitzes and Mutran, 2004). 
The paper has some limitations. First, the fixed effects regression approach did not permit the inclusion of institutional variables that could capture differences in the pension systems. This restricts the possibility of drawing specific policy conclusions based on this paper or comparing different institutional contexts. Moreover, the choice to carry out the analysis on a pooled sample of 11 European countries is due to the small sample size. I am aware that contextual differences between countries can affect people's response to life changes and subjective wellbeing; however, deciding to focus on one or a few countries would have greatly decreased the sample size, invalidating its statistical power. Future literature should analyse data on individual countries or focus on the differences between different institutional contexts. A second limitation is that I use a self-reported measure to distinguish between being employed/unemployed or retired, and exclude those respondents who report themselves differently (e.g. as being a home-maker). I recognise that the self-reported measure of the work status can differ from administrative data. It is possible that respondents from the sample that consider themselves not retired but receive pension benefits have been excluded. Finally, it would also be interesting to use other indicators to measure the level of wellbeing or to investigate the effect of other life domains (such as the family trajectory) on female life satisfaction.

Despite these limitations, this study has many strengths. It offers advances in terms of new research questions and methods. First, I considered patterns of employment from youth to middle age. Using sequence analysis, I was able to observe the differences in women's work trajectories over 30 years. This technique allows us to differentiate careers characterised by full-time employment, part-time work, and a combination of paid work and long or short breaks. The clustering provides a parsimonious model that allows the association between life events and later-life outcomes to be studied (Zella and Harper,2020). Second, due to the richness of the SHARE data, I was able to take into account the changes in life satisfaction, taking into account important covariates. Results show that the retirement transition affects the level of life satisfaction differently, depending on the longitudinal working trajectories. Therefore, through the application of a recent methodological approach to handling lifecourse information, I can broadly enlarge the perspective on the work models typically followed by women and on the outcomes they have in old age. From a lifecourse perspective, the question of how different types of work patterns can influence future outcomes (e.g. life satisfaction) can now be addressed in a new and very promising way. Sequence analysis provides a rigorous methodology for visualising and interpreting work (and other) trajectories as process outcomes, and fixed effects regression models make it possible to observe the intra-individual changes. My results focus attention on the relevant question of how women can combine work and family, and how this combination can influence the structure of their working career and, consequently, their wellbeing in later life. Moreover, it would be extremely important to think about how social policies could advance wellbeing, considering how they could play a role in shaping individual and context-specific trajectories.

Financial support. This research received no specific grant from any funding agency, commercial or not-for-profit sectors.

Conflict of interest. The author declares no conflicts of interest. 


\section{Notes}

1 The three other cost specifications tested were: (a) optimal matching with substitution costs derived from transition rates between the states, (b) the dynamic Hamming distance (Lesnard, 2010), and (c) the simple Hamming distance. Because the clustering yielded slightly better cut-off criteria, optimal matching was retained for the final specification.

2 The silhouette is a graphical display for evaluating the quality of different cluster solutions. 'Each cluster is represented by a so-called silhouette, which is based on the comparison of its tightness and separation. This silhouette shows which objects lie well within their cluster, and which ones are merely somewhere in between clusters. The entire clustering is displayed by combining the silhouettes into a single plot, allowing an appreciation of the relative quality of the clusters and an overview of the data configuration. The average silhouette width provides an evaluation of clustering validity, and might be used to select an "appropriate" number of clusters' (Rousseeuw, 1987: 53).

3 All calculations for this part of the analysis were conducted using the R statistical software (R Core Team, 2012), the TraMineR libraries for the sequence analysis (Gabadinho et al., 2011) and WeightedCluster for the cluster analysis (Studer, 2013).

4 The construction of this variable was inspired by the work of Heybroek et al. (2015) who created it to study changes in life satisfaction across retirement transition.

\section{References}

Abbott A and Hrycak A (1990) Measuring resemblance in sequence data: an optimal matching analysis of musicians' careers. American Journal of Sociology 96, 144-185.

Abbott A and Tsay A (2000) Sequence analysis and optimal matching methods in sociology: review and prospect. Sociological Methods \& Research 29, 3-33.

Adams GA, Prescher J, Beehr TA and Lepisto L (2002) Applying work-role attachment theory to retirement decision-making. International Journal of Aging and Human Development 54, 125-137.

Ashforth BE (2001) Role Transitions in Organizational Life: An Identity-based Perspective. Mahwah, NJ: Erlbaum.

Atchley RC (1971) Retirement and leisure participation: continuity or crisis? The Gerontologist 11, 13-17.

Atchley RC (1976) The Sociology of Retirement. New York, NY: John Wiley \& Sons.

Atchley RC (1982) Retirement as a social institution. Annual Review of Sociology 8, 263-287.

Atchley RC (1993) Continuity theory and the evolution of activity in later adulthood. In Kelly JR (ed.), Activity and Aging: Staying Involved in Later Life. Newbury Park, CA: Sage, pp. 5-16.

Atchley RC (1999) Continuity and Adaptation in Aging: Creating Positive Experiences. Baltimore, MD: Johns Hopkins University Press.

Bambra C and Eikemo TA (2009) Welfare state regimes, unemployment and health: a comparative study of the relationship between unemployment and self-reported health in 23 European countries. Journal of Epidemiology \& Community Health 63, 92-98.

Barer BM (1994) Men and women aging differently. International Journal of Aging and Human Development 38, 29-40.

Bender KA and Jivan NA (2005) What Makes Retirees Happy? Center for Retirement Research at Boston College, Boston.

Bennett J and Moehring K (2015) Cumulative (dis) advantage? The impact of labour market policies on late career employment from a life course perspective. Journal of Social Policy 44, 213-233.

Billari FC and Piccarreta R (2005) Analyzing demographic life courses through sequence analysis. Mathematical Population Studies 12, 81-106.

Blossfeld HP, Buchholz S and Hofäcker D (eds) (2006) Globalization, Uncertainty and Late Careers in Society. Abingdon, UK: Routledge.

Brugiavini A, Orso CE, Genie MG, Naci R and Pasini G (2019) Combining the retrospective interviews of wave 3 and wave 7: the third release of the SHARE Job Episodes Panel. Munich Center for the Economics of Aging (MEA), Munich, SHARE Working Paper Series 36-2019.

Buchholz S, Rinklake A, Schilling J, Kurz K, Schmelzer P and Blossfeld HP (2011) Aging populations, globalization and the labor market: comparing late working life and retirement in modern societies. In Aging Populations, Globalization and the Labor Market. Cheltenham, UK: Edward Elgar Publishing, 3-32 
Byles J, Tavener M, Robinson I, Parkinson L, Smith PW, Stevenson D, Leigh L and Curryer C (2013) Transforming retirement: new definitions of life after work. Journal of Women \& Aging 25, 24-44.

Calasanti TM (1993) Bringing in diversity: toward an inclusive theory of retirement. Journal of Aging Studies 7, 133-150.

Calasanti TM (1996) Gender and life satisfaction in retirement: an assessment of the male model. Journals of Gerontology: Psychological Sciences and Social Sciences 51B, S18-S29.

Calvo E, Madero-Cabib I and Staudinger UM (2018) Retirement sequences of older Americans: moderately destandardized and highly stratified across gender, class, and race. The Gerontologist 58, 1166-1176.

Carter MAT and Cook K (1995) Adaptation to retirement: role changes and psychological resources. Career Development Quarterly 44, 67-82.

Chandola T, Brunner E and Marmot M (2006) Chronic stress at work and the metabolic syndrome: prospective study. British Medical Journal 332, 521-525.

Cinamon RG and Rich Y (2002) Gender differences in the importance of work and family roles: implications for work-family conflict. Sex Roles 47, 531-541.

Clausen JA and Gilens M (1990) Personality and labor force participation across the life course: a longitudinal study of women's careers. Sociological Forum 5, 595-618.

Cornwell B (2015) Social Sequence Analysis: Methods and Applications (Vol. 37). New York, NY: Cambridge University Press.

Crowley JE (1985) Longitudinal effects of retirement on men's psychological and physical well-being. In Parnes HS (ed). Retirement Among American Men. Lexington, MA: Lexington Books, pp. 147-173.

Dahl E and Birkelund GE (1997) Health inequalities in later life in a social democratic welfare state. Social Science \& Medicine 44, 871-881.

Damman M, Henkens K and Kalmijn M (2011) The impact of midlife educational, work, health, and family experiences on men's early retirement. Journals of Gerontology: Psychological Sciences and Social Sciences 66B, 617-627.

Damman M, Henkens K and Kalmijn M (2015) Missing work after retirement: the role of life histories in the retirement adjustment process. The Gerontologist 55, 802-813.

Dave D, Rashad I and Spasojevic J (2008) The Effects of Retirement on Physical and Mental. Southern Economic Journal, 75, 497 - 523

De Vaus D and Wells Y (2004) What should mature age workers do to promote health and wellbeing in retirement. Health Issues 80, 23-26.

Diener E (2009) Subjective well-being. In Diener E. (eds) The Science of Well-Being. Social Indicators Research Series, vol. 37. Dordrecht: Sprigner, pp. 11-58.

Diener ED, Emmons RA, Larsen RJ and Griffin S (1985) The satisfaction with life scale. Journal of Personality Assessment 49, 71-75.

Dingemans E and Möhring K (2019) A life course perspective on working after retirement: what role does the work history play? Advances in Life Course Research 39, 23-33.

Drentea P (2002) Retirement and mental health. Journal of Aging and Health 14, 167-194.

Dwyer DS and Mitchell OS (1999) Health problems as determinants of retirement: are self-rated measures endogenous? Journal of Health Economics 18, 173-193.

Ebbinghaus B (2006) Reforming Early Retirement in Europe, Japan and the USA. Oxford: Oxford University Press.

Ebbinghaus B and Hofäcker D (2013) Reversing early retirement in advanced welfare economies. A paradigm shift to overcome push and pull factors. Comparative Population Studies 38, 807-804.

Ekerdt DJ (2010) Frontiers of research on work and retirement. Journals of Gerontology: Psychological Sciences and Social Sciences 65B, 69-80.

Elder, GH (1995) The life course paradigm: Social change and individual development, In Moen P, Elder GH and Luscher K (Eds.), Examining lives in context: Perspectives on the ecology of human development Washington, DC: APA Press, pp. 101-139.

Elder GH and Johnson MK (2003) The life course and aging: challenges, lessons, and new directions. In Invitation to the Life Course: Toward New Understandings of Later Life. New York: Routledge, pp. 49-81.

Elder GH, Johnson MK and Crosnoe R (2003) The emergence and development of life course theory. In Mortimer JT and Shanahan MJ (eds). Handbook of the Life Course. Handbooks of Sociology and Social Research. Boston, MA: Springer, pp. 3-19. 
Fadila DES and Alam RR (2016) Factors affecting adjustment to retirement among retirees' elderly persons. Journal of Nursing Education and Practice 6, 112-122.

Foster L (2011) Privatisation and pensions: what does this mean for women? Journal of Poverty and Social Justice 19, 103-115.

Freedman M (1999) Prime Time: How Baby Boomers Will Revolutionize Retirement and Transform America. New York, NY: Public Affairs.

Fry PS (1992) Major social theories of aging and their implications for counseling concepts and practice: a critical review. The Counseling Psychologist 20, 246-329.

Gabadinho A, Ritschard G, Mueller NS and Studer M (2011) Analyzing and visualizing state sequences in $\mathrm{R}$ with TraMineR. Journal of Statistical Software 40, 1-37.

Gauthier JA, Widmer ED, Bucher $\mathbf{P}$ and Notredame C (2010) 1. Multichannel sequence analysis applied to social science data. Sociological Methodology 40, 1-38.

George LK (1992) Economic status and subjective well-being: a review of the literature and an agenda for future research. In Cutler NE, Gregg DW and Lawton MP (eds), Aging, Money, and Life Satisfaction: Aspects of Financial Gerontology. New York, NY: Springer, pp. 69-99.

Hansen HT and Lorentzen T (2019) Work and welfare-state trajectories in Norway over two decades: has the goal of getting more people into work been achieved? International Journal of Social Welfare 28, 246-259.

Haring-Hidore M, Stock WA, Okun MA and Witter RA (1985) Marital status and subjective well-being: a research synthesis. Journal of Marriage and the Family 47, 947-953.

Hatch LR and Thompson A (1992) Family responsibilities and women's retirement. In Szinovacz M, Ekerdt DJ and Vinick BH (eds). Families and Retirement. Newbury Park, CA: Sage, pp. 99-113.

Hennig C and Liao TF (2013) How to find an appropriate clustering for mixed-type variables with application to socio-economic stratification. Journal of the Royal Statistical Society: Series C (Applied Statistics) 62, 309-369.

Henning G, Lindwall M and Johansson B (2016) Continuity in well-being in thetransition to retirement. GeroPsych: The Journal of Gerontopsychology andGeriatric Psychiatry 59, 225-237

Hershey DA and Henkens K (2014) Impact of different types of retirement transitions on perceived satisfaction with life. The Gerontologist 54, 232-244.

Herzog AR and Rodgers WL (1981) Age and satisfaction: data from several large surveys. Research on Aging 3, 142-165.

Herzog A, House JS and Morgan JN (1991) Relation of work and retirement to health and well-being in older age. Psychology and Aging 6, 202-211.

Hetschko C, Knabe A and Schöb R (2014) Changing identity: retiring from unemployment. The Economic Journal 124, 149-166.

Heybroek L, Haynes M and Baxter J (2015) Life satisfaction and retirement in Australia: a longitudinal approach. Work, Aging and Retirement 1, 166-180.

Hilbourne M (1999) Living together full time? Middle-class couples approaching retirement. Ageing \& Society 19, 161-183.

Holden KC and Kuo HHD (1996) Complex marital histories and economic well-being: the continuing legacy of divorce and widowhood as the HRS cohort approaches retirement. The Gerontologist 36, 383-390.

Horner EM (2014) Subjective well-being and retirement: analysis and policy recommendations. Journal of Happiness Studies 15, 125-144.

Isaksson K and Johansson G (2000) Adaptation to continued work and early retirement following downsizing: long-term effects and gender differences. Journal of Occupational and Organizational Psychology 73, 241-256.

Jæger MM and Holm A (2004) How Stressful is Retirement? New Evidence from a Longitudinal, Fixed-effects Analysis. Copenhagen: Centre for Applied Microeconometrics.

Kaskie B, Imhof S, Cavanaugh J and Culp K (2008) Civic engagement as a retirement role for aging Americans. The Gerontologist 48, 368-377.

Kim JE and Moen P (2001) Is retirement good or bad for subjective well-being? Current Directions in Psychological Science 10, 83-86.

Kim JE and Moen P (2002) Retirement transitions, gender, and psychological well-being: a life-course, ecological model. Journals of Gerontology: Psychological Sciences and Social Sciences 57B, 212-222. 
König S (2017) Career histories as determinants of gendered retirement timing in the Danish and Swedish pension systems. European Journal of Ageing 14, 397-406.

Kurdek LA (1991) The relations between reported well-being and divorce history, availability of a proximate adult, and gender. Journal of Marriage and the Family 53, 71-78.

Latif E (2011) The impact of retirement on psychological well-being in Canada. Journal of Socio-economics 40, 373-380.

Lesnard L (2010) Setting cost in optimal matching to uncover contemporaneous socio-temporal patterns. Sociological Methods \& Research 38, 389-419.

Luhmann M, Hofmann W, Eid M and Lucas RE (2012) Subjective well-being and adaptation to life events: a meta-analysis. Journal of Personality and Social Psychology 102, 592-615.

Macmillan R (ed.) (2005) The Structure of the Life Course: Standardized? Individualized? Differentiated? Amsterdam: Elsevier.

Mayring P (2000) Retirement as crisis or good fortune? Results of a quantitative-qualitative longitudinal study. Zeitschrift für Gerontologie und Geriatrie 33, 124-133.

Mein G, Martikainen P, Hemingway H, Stansfeld S and Marmot M (2003) Is retirement good or bad for mental and physical health functioning? Whitehall II longitudinal study of civil servants. Journal of Epidemiology \& Community Health 57, 46-49.

Midanik LT, Soghikian K, Ransom LJ and Tekawa IS (1995) The effect of retirement on mental health and health behaviors: the Kaiser Permanente Retirement Study. Journals of Gerontology: Psychological Sciences and Social Sciences 50B, S59-S61.

Moen P (2001) The gendered life course. In Binstock RH and George LK (eds), Handbook of Aging and the Social Sciences. San Diego, CA: Academic Press, pp. 179-196.

Moen P and Chermack K (2005) Gender disparities in health: strategic selection, careers, and cycles of control. Journals of Gerontology: Psychological Sciences and Social Sciences 60B, S99-S108.

Moen P, Dempster-McClain D and Williams Jr RM (1992) Successful aging: a life-course perspective on women's multiple roles and health. American Journal of Sociology 97, 1612-1638.

Moen P, Erickson MA and Dempster-McClain D (2000) Social role identities among older adults in a continuing care retirement community. Research on Aging 22, 559-579.

Newman ES, Sherman SR and Higgins CE (1982) Retirement expectations and plans: a comparison of professional men and women. In Szinovacz ME (ed). Women's Retirement: Policy Implications of Recent Research. Beverly Hills, CA: Sage, pp. 113-122.

O'Rand AM, Henretta JC and Krecker ML (1992) Family pathways to retirement. In Szinovacz M, Ekerdt DJ and Vinick BH (eds). Families and Retirement. Newbury Park, CA: Sage, pp. 81-98.

Petters JS and Asuquo PN (2008) Work-role attachment and retirement intentions of public school teachers in Calabar, Nigeria. Studies on Home and Community Science 2, 11-17.

Pienta A (1999) Early childbearing patterns and women's labor force behavior in later life. Journal of Women \& Aging 11, 69-84.

Pienta AM, Burr JA and Mutchler JE (1994) Women's labor force participation in later life: the effects of early work and family experiences. Journal of Gerontology 49, S231-S239.

Pinquart M and Schindler I (2009) Change of leisure satisfaction in the transition to retirement: a latentclass analysis. Leisure Sciences 31, 311-329.

Ponomarenko V (2016) Cumulative disadvantages of non-employment and non-standard work for career patterns and subjective well-being in retirement. Advances in Life Course Research 30, 133-148.

Ponomarenko V, Leist AK and Chauvel L (2019) Increases in wellbeing in the transition to retirement for the unemployed: catching up with formerly employed persons. Ageing \& Society 39, 254-276.

Price CA (1998) Women and Retirement: The Unexplored Transition. New York, NY: Garland Publishing.

Price CA and Joo E (2005) Exploring the relationship between marital status and women's retirement satisfaction. International Journal of Aging and Human Development 61, 37-55.

Price CA and Nesteruk O (2010) Creating retirement paths: examples from the lives of women. Journal of Women \& Aging 22, 136-149.

Quick HE and Moen P (1998) Gender, employment and retirement quality: a life course approach to the differential experiences of men and women. Journal of Occupational Health Psychology 3, 44-64.

Radl J (2014) Retirement Timing and Social Stratification: A Comparative Study of Labor Market Exit and Age Norms in Western Europe. Berlin: Walter de Gruyter. 
R Core Team (2012) R: A Language and Environment for Statistical Computing. Vienna: R Foundation for Statistical Computing.

Reitzes DC and Mutran EJ (2004) The transition to retirement: stages and factors that influence retirement adjustment. International Journal of Aging and Human Development 59, 63-84.

Reitzes DC, Mutran EJ and Fernandez ME (1994) Middle-aged working men and women: similar and different paths to self-esteem. Research on Aging 16, 355-374.

Reitzes DC, Mutran EJ and Fernandez ME (1996) Does retirement hurt well-being? Factors influencing self-esteem and depression among retires and workers. The Gerontologist 36, 649-656.

Richardson VE (1999) Women and retirement. Journal of Women \& Aging 11, 49-66.

Richardson V and Kilty KM (1991) Adjustment to retirement: continuity vs. discontinuity. International Journal of Aging and Human Development 33, 151-169.

Riley MW and Riley Jr JW (1994) Structural lag: past and future. In Riley MW, Kahn RL and Foner A (eds), Age and Structural Lag: The Mismatch Between People's Lives and Opportunities in Work, Family, and Leisure. New York, NY: Wiley, pp. 15-36.

Rousseeuw PJ (1987) Silhouettes: a graphical aid to the interpretation and validation of cluster analysis. Journal of Computational and Applied Mathematics 20, 53-65.

Ryser VA and Wernli B (2017) How does transitioning into retirement impact the individual emotional system? Evidence from the Swiss context. Advances in Life Course Research 32, 42-54.

Settersten RA (2003) Invitation to the Life Course: Toward New Understandings of Later Life. Amityville, NY: Baywood.

Shin DC and Johnson DM (1978) Avowed happiness as an overall assessment of the quality of life. Social Indicators Research 5, 475-492.

Simmons BA and Betschild MJ (2001) Women's retirement, work and life paths: changes, disruptions and discontinuities. Journal of Women \& Aging 13, 53-70.

Slevin KF and Wingrove CR (1995) Women in retirement: a review and critique of empirical research since 1976. Sociological Inquiry 65, 1-21.

Sorensen A (1983) Women's employment patterns after marriage. Journal of Marriage and the Family 45, 311-321.

Studer M (2013) WeightedCluster library manual: a practical guide to creating typologies of trajectories in the social sciences with R. University of Geneva Institute for Demographic and Life Course Studies, Geneva, LIVES Working Papers 24.

Szinovacz ME (2003) Contexts and pathways: retirement as institution, process, and experience. In Adams GA and Beehr TA (eds). Retirement: Reasons, Processes, and Results. New York: Springer, pp. 6-52.

Szinovacz ME and Davey A (2006) Effects of retirement and grandchild care on depressive symptoms. International Journal of Aging and Human Development 62, 1-20.

Szinovacz M and Ekerdt DJ (1995) Families and retirement. In Blieszner R and Bedford VH (eds), Handbook of Aging and the Family. Westport, CT: Greenwood Press, pp. 375-400.

Van Solinge H (2015) Retirement, adjustment to. In Whitbourne SK (ed). The Encyclopedia of Adulthood and Aging. New York: John Wiley \& Sons, pp. 1-5.

Van Solinge H and Henkens K (2005) Couples' adjustment to retirement: a multi-actor panel study. Journals of Gerontology: Psychological Sciences and Social Sciences 60B, S11-S20.

Van Solinge $\mathbf{H}$ and Henkens $\mathbf{K}$ (2008) Adjustment to and satisfaction with retirement: two of a kind? Psychology and Aging 23, 422-434.

Von Bonsdorff ME, Shultz KS, Leskinen E and Tansky J (2009) The choice between retirement and bridge employment: a continuity theory and life course perspective. International Journal of Aging and Human Development 69, 79-100.

Wahrendorf M (2015) Previous employment histories and quality of life in older ages: sequence analyses using SHARELIFE. Ageing \& Society 35, 1928-1959.

Wahrendorf M, Dragano N and Siegrist J (2013) Social position, work stress, and retirement intentions: a study with older employees from 11 European countries. European Sociological Review 29, 792-802.

Wahrendorf M, Akinwale B, Landy R, Matthews K and Blane D (2017) Who in Europe works beyond the state pension age and under which conditions? Results from SHARE. Journal of Population Ageing 10, 269-285. 
Wang M (2007) Profiling retirees in the retirement transition and adjustment process: examining the longitudinal change patterns of retirees' psychological well-being. Journal of Applied Psychology 92, 455474 .

Wang M, Zhan Y, Liu S and Shultz KS (2008) Antecedents of bridge employment: a longitudinal investigation. Journal of Applied Psychology 93, 818-830.

Wang M, Henkens $\mathbf{K}$ and van Solinge $\mathbf{H}$ (2011) Retirement adjustment: a review of theoretical and empirical advancements. American Psychologist 66, 204-213.

Ward Jr JH (1963) Hierarchical grouping to optimize an objective function. Journal of the American Statistical Association 58, 236-244.

Warr P, Butcher V, Robertson I and Callinan M (2004) Older people's well-being as a function of employment, retirement, environmental characteristics and role preference. British Journal of Psychology 95, 297-324.

Wetzel M, Huxhold $\mathbf{O}$ and Tesch-Römer C (2016) Transition into retirement affects life satisfaction: short- and long-term development depends on last labor market status and education. Social Indicators Research 125, 991-1009.

Widmer ED and Ritschard G (2009) The de-standardization of the life course: are men and women equal? Advances in Life Course Research 14, 28-39.

Wolcott I (1998) Families in Later Life: Dimensions of Retirement. Melbourne: Australian Institute of Family Studies.

Zella S and Harper S (2020) The impact of life course employment and domestic duties on the wellbeing of retired women and the social protection systems that frame this. Journal of Aging and Health 32, 285-295.

Cite this article: Tambellini E (2021). Exploring the relationship between working history, retirement transition and women's life satisfaction. Ageing \& Society 1-30. https://doi.org/10.1017/S0144686X2100132X 